\title{
EDITORIAL
}

\section{MUJER, DERECHOS HUMANOS Y SALUD}

\section{Cristina Pérez Andrés}

Subdirección General de Epidemiología, Promoción y Educación para la Salud. Dirección General de Salud Pública. Ministerio de Sanidad y Consumo.

En el transcurso del $50^{\circ}$ aniversario de la aprobación de la Declaración Universal de los Derechos Humanos ${ }^{1}$ y coincidiendo este número de la Revista Española de Salud Pública con el mes en el que se celebra el Día Internacional de la Mujer, consideramos propicio dedicar este editorial a la salud de la mitad de la humanidad, aquella que es de género femenino.

Para hablar de ello no consideramos necesaria una definición correcta de salud, porque si así fuera este editorial no se podría llevar a cabo. La salud forma parte de los valores de la vida, siendo una cualidad fundamental de la misma que la condiciona en duración y calidad pero para la que, como para otros valores, es imposible encontrar una definición que la caracterice y que sirva para cualquier lugar y tiempo. En cuanto a la definición que la OMS da de la salud (completo estado de bienestar físico, psíquico y social y no la mera ausencia de enferme$d a d)$, se puede admitir que sirve para la gestión y de la que cabe deducir indicadores útiles para medir sus resultados, pero no la salud misma.

El ser humano es un organismo biológico, psicológico y social que, desde que nace, debe las características de su existencia, incluyendo la salud, a las relaciones internas y externas que mantiene con él mismo y con su entorno. Las relaciones externas las establece tanto con el medio ambiente en el que habita como con los individuos de su misma especie. Las primeras contribuyen al mante- nimiento de su fisiología y las realiza a través de los alimentos que ingiere, el aire que respira, las sustancias que contactan con su piel y sus mucosas... Las que mantiene con otras personas las realiza a través de su psiquismo y afectan al área intelectual y sentimental.

La salud de la que puede disponer una persona depende de factores individuales y socioambientales, estableciéndose un sistema de relaciones entre los tres niveles que los hace interdependientes. Los factores individuales podrán o no ser controlados a nivel personal, dependiendo de su origen genético o adquirido. Los factores socioambientales se refieren a aquellos que afectan no a los individuos directamente, sino a la sociedad que ellos forman, pero que repercuten también en el nivel individual de salud, incidiendo y reflejándose en ella.

En contra de la opinión negativa de algunas personas sobre los programas de discriminación positiva para grupos concretos de la sociedad, está la de aquellos que defendemos su existencia, porque deben servir para disminuir la discriminación negativa que los justifican. La situación de la mujer todavía hoy requiere que dichos programas contrarresten la tendencia general de la sociedad a obviar en ella el cumplimiento de los Derechos Humanos y la repercusión negativa que ello tiene para su salud.

En el ámbito de la salud podemos tratar el tema de la discriminación de la mujer desde el punto de vista de una serie de indicadores sanitarios y socioeconómicos ${ }^{2}$. Con ellos 
se constatan datos acerca de la discriminación negativa de la mujer en los siguientes campos: la investigación epidemiológica, que hasta hace poco no ha incluido a las mujeres en sus muestras, por lo que se conocen peor en ellas los condicionantes de la salud y la enfermedad; la asistencia sanitaria, tanto en actividades diagnósticas como terapéuticas (buen ejemplo de ello es el menor número de mujeres que reciben un órgano para trasplante en relación al número de los que obtienen los hombres). Por otra parte, también los indicadores socioeconómicos condicionantes de los niveles de salud, tales como la tasa de actividad, la tasa de paro, el analfabetismo y nivel de estudios, son siempre desfavorables para la mujer con respecto al hombre. En el período 1985-1993 mientras que la tasa de paro en el hombre creció el $7,3 \%$ en la mujer lo hizo en el $14,9 \%$. Los indicadores de salud y calidad de vida por sexo sólo son mejores para la mujer en el caso del de la esperanza de vida. Sin embargo los años que la mujer vive más que el hombre, son años con baja calidad de vida, a causa de enfermedades $\mathrm{c}$ incapacidades.

Además de la situación mostrada por los indicadores, es imprescindible tener en cuenta la concepción que de vida saludable tienen las mujeres. Las participantes en los grupos de discusión llevados a cabo para el Informe sobre la salud y la mujer en la Comunidad de Madrid ${ }^{3}$, realizado por la Consejería de Sanidad y Bienestar Social, asocian la calidad de vida más que con la salud con lo saludable, concretando esta asociación en la expresión vida saludable, que ellas utilizan para nombrar el ideal a conseguir, al tiempo que identifican el término "salud" con las actividades que se realizan en las instituciones sanitarias.

Según el estudio citado, por vida saludable entienden las mujeres la oportunidad cotidiana de mantener relaciones con los demás. Estas relaciones se propician cuando se cumple, entre otros, el artículo 23 de la Declaración Universal de los Derechos Humanos: 1. Toda persona tiene derecho al trabajo, a la libre elección de su trabajo, a condiciones equitativas y satisfactorias de trabajo y a la protección contra el desempleo. 2. Toda persona tiene derecho, sin discriminación alguna, a igual salario por trabajo igual. 3. Toda persona que trabaja tiene derecho a una remuneración equitativa y satisfactoria, que le asegure, asi como a su familia, una existencia conforme a la dignidad humana y que será completada, en caso necesario, por cualesquiera otros medios de protección social. 4. Toda persona tiene derecho a fundar sindicatos y a sindicarse para la defensa de sus intereses.

La mujer tiene derecho a trabajar fuera de su propio hogar, ya que el trabajo de la casa, que es productivo aunque no remunerado, es el que más adolece de lo que las mujeres identifican con los elementos imprescindibles para llevar a cabo una vida saludable, esto es, las relaciones con los demás. Las que mantienen las mujeres que sólo trabajan en el hogar, suelen establecerlas exclusivamente con las personas de su familia o del entorno de la misma, sin poder ver ampliado su círculo a individuos que les permitan otras relaciones de distinta índole, en las que la mujer pueda desarrollarse y expresarse sin prejuicios ni temores, al igual que lo hacen el resto de los miembros de su familia en sus diferentes relaciones sociales. Las mujeres de esta investigación nombran, junto a su concepción de vida saludable, un sujeto plural: "nosotros", e identifican lo saludable con una vida más autónoma y responsable, articulada con la educación como proceso de aprendizaje evolutivo.

Coincidiendo con el discurso de los grupos de discusión de mujeres para la investigación citada, en el estudio de las desigualdades en salud el tipo de ocupación es, junto con el nivel de estudios, el indicador de clase social más utilizado y de más importancia, pretendiendo medir con el mismo la experiencia vital del individuo en relación a su medio social ${ }^{4}$.

Mientras que entre el hombre y la mujer no se lleven a cabo el reparto de las tareas domésticas y las del cuidado de los hijos, se in- 
cumplirá también el artículo 24 de la Declaración Universal de los Derechos Humanos: toda persona tiene derecho al descanso, al disfrute del tiempo libre, a una limitación razonable de la duración del trabajo y a vacaciones periódicas pagadas. Y tampoco se respetará el articulo 27: toda persona tiene derecho a tomar parte libremente de la vida cultural de la comunidad, a gozar de las artes y a participar en el progreso científico y en los beneficios que de él resulten.

Si la mujer no dispone, como el hombre, de un espacio de relaciones ajeno a su hogar, si no goza de la misma independencia económica que él, ni del mismo tiempo libre, es difícil que se respeten los artículos de la Declaración Universal de los Derechos $\mathrm{Hu}$ manos que protegen su formación, evolución y desarrollo. Y por lo tanto, es difícil para la mujer tener el mismo acceso que el hombre a lo que ella misma considera una vida saludable.

Además de los artículos de la Declaración Universal de los Derechos Humanos ya citados en este editorial, la discriminación de la mujer se objetiva en el incumplimiento de los siguientes puntos de la misma Declaración: el 2.1: Toda persona tiene todos los derechos y libertades proclamados en esta Declaración, sin distinción alguna de raza, color, sexo, idioma, religión, opinión política o de cualquier otra índole, origen nacional o social, posición económica, nacimiento o cualquier otra condición; el artículo 3: Todo individuo tiene derecho a la vida, a la libertad y a la seguridad de su persona; el 4: $\mathrm{Na}$ die estará sometido a esclavitud ni a servidumbre; la esclavitud y la trata de esclavos están prohibidas en todas sus formas; el 5: Nadie será sometido a torturas ni a penas o tratos crueles inhumanos o degradan- tes; el 7: Todos son iguales ante la ley y tienen, sin distinción, derecho a igual protección de la ley. Todos tienen derecho a igual protección contra toda discriminación que infrinja esta Declaración contra toda provocación a tal discriminación y el 16.1: Los hombres y las mujeres, a partir de la edad núbil, tienen derecho, sin restricción alguna por motivos de raza, nacionalidad o religión, a casarse y fundar una familia; y disfrutarán de iguales derechos en cuanto al matrimonio, durante el matrimonio y en caso de disolución del matrimonio.

Con el incumplimiento de estos artículos de la Declaración Universal de los Derechos Humanos se va, pues, en contra de la vida saludable para la mujer, favoreciéndose con ello las desigualdades en salud para las personas que constituyen la mitad de la humanidad.

\section{BIBLIOGRAFIA}

1. Declaración Universal de los Derechos Humanos. Aprobada y proclamada por la Asamblea General de las Naciones Unidas el 10 de Diciembre de 1948.

2. Regidor E, Rodríguez C, Gutiérrez Fisac JL. Indicadores de salud. Tercera cvaluación cn España del Programa Regional Europeo Salud para Todos. Madrid Ministerio de Sanidad y Consumo; 1995.

3. Conde Gutiérrez F. Informe sobre la salud y la mujer en la Comunidad de Madrid. Madrid: Consejería de Sanidad y Servicios sociales; 1996. Documento Técnico de Salud pública núm 32.

4. Navarro V y Benach J. Desigualdades de salud en España. Rev Esp Salud Pública 1996; 70: 505-636. 